\title{
Perceptions of Relevant Stakeholders towards the Impact of Climate Change Policy on Aquaculture Activities in Malaysia: Some Preliminary Findings
}

\author{
Chee Sheng Woon, Carolyn Payus, Leong Wan Vun, and Wei Peng Lee
}

\begin{abstract}
The aquaculture sector started in Malaysia since 1920s and has developed quickly nationwide. Sustainability of aquaculture depends on its adaptability to environmental changes. This research includes the study on the impact of the National Policy on Climate Change on the aquaculture industry. Policy appraisal and impact assessment approach have been carried out by having experts' interview and survey questionnaires. The Policy is expected to promote aquaculture sector according to its principles, strategic trusts and key actions. In line with this, the respondents suggested several criteria for the aquaculture sector to be climate resilient and hence developed in a sustainable manner. The results from analysing the Policy and the suggestions from respondents are expected to aid developing a climate-resilient aquaculture system model. Hence, better understanding of the potential climate change policy impact on aquaculture enables the policy-makers and stakeholders to plan and implement possible countering measures to achieve sustainability in aquaculture.
\end{abstract}

Index Terms-Aquaculture, climate change policy, climate resilient aquaculture, policy impact.

\section{INTRODUCTION}

Aquaculture is referred to as the farming of aquatic organisms that implies some form of intervention in the rearing process to enhance its production whereby the output from aquaculture activities are designated for final harvest for consumption [1]. From the historical point of view, aquaculture evolved as modern agriculture in areas of Asia, the Pacific and Europe where the carrying capacities of the traditional agro- and aquatic ecosystems could no longer support the dense human populations [2].

Aquaculture has been developed in Malaysia since 1920s started with the freshwater aquaculture and then brackish water aquaculture in the late 1930s [3]. The sector has developed quickly and has become an important activity in Malaysia [4] although the different climatic and natural conditions within states in Malaysia have impacts on its production [3]. The estimated wholesale value of aquaculture production in 2000 was RM 970,322.89 while in 2015 the value reached RM 3,296,463.33 [5]. Hence, it can be inferred that the aquaculture sector nowadays has become one of the

\footnotetext{
Manuscript received November 7, 2016; revised February 14, 2017. This work was financially supported Malaysian Ministry of Higher Education under Grant NRGS0005.

The authors are with the Environmental Science Programme, Faculty of Science and Natural Resources, Universiti Malaysia Sabah, Jalan UMS, 88400, Kota Kinabalu, Sabah, Malaysia (e-mail: vincent_91cs@outlook.com, melpayus@ums.edu.my, bvun@ums.edu.my, sky_blue9115@hotmail.my).
}

important contributors to the economic growth in Malaysia.

Sustainability of aquaculture activities depends on its adaptability to environmental changes. Therefore, aquaculture requires specific adaptation and mitigation measures because the rate of future climate change is predicted to be more rapid than previous natural changes and the resilience of species and systems is being compromised by a number of concurrent pressures (fishing, loss of genetic diversity, habitat destruction, pollution, introduced and invasive species and pathogens) [6]. It is crucial to study the impacts of climate change as its effects is still in dubio.

The Malaysian Government has launched the National Policy on Climate Change in 2010. The policy serves as a framework of mobilising and guiding stakeholders to work in a comprehensive and integrated way in addressing the challenges of climate change and hence climate-resilient development can be realised with the effective institutional capacity via collaborative participation which based on indigenous and scientific knowledge [7]. Thus, there is a need to study the relationship between the policy and aquaculture sector in order to help building climatic resilience in aquaculture.

The National Policy on Climate Change is expected to aid developing a climate-resilient aquaculture system model which is able to remain sustainable with the challenges from climate change. Hence, better understanding of the potential climate change impact mechanisms will enable the policy-makers and stakeholders to plan and implement possible countering measures to achieve sustainability in aquaculture industry.

\section{MethodolOGY}

\section{A. Survey Questionnaire}

This research includes the study on the impact of the National Policy on Climate Change and any other changes that might have short- and long-term effect on the aquaculture industry. This was done through policy appraisal and impact assessment approach by having experts' interview and surveys.

The survey questionnaire form has been distributed via email to 50 experts from various fields including aquaculture experts, climate change experts and policymakers. The respondents were given two weeks to fill in the survey questionnaire form. The responses from the respondents were later compiled for further analysis and discussion.

Five respondents have responded to the survey questionnaire. The responses are tabulated and analysed by 
section. Responses are supported by evidences obtained from documents review and related to the principles $(\mathrm{P})$, strategic thrusts (ST) and key actions (KA) of the National Policy on Climate Change. This is to enhance the reliability and validity of the responses.

\section{The National Policy On Climate Change}

Under funding from the Ninth Malaysia Plan and joint implementation by the Conservation and Environmental Management Division (CEMD) and Institute for Environment and Development (LESTARI), Universiti Kebangsaan Malaysia (UKM), the National Policy on Climate Change was drafted since 2005 and then being launched in 2010. The policy aims to ensure climate-resilient development to fulfil national aspirations for sustainability with the following objectives [7]:

TABLE I: PRINCIPLE (P), STRATEGIC THRUST (ST) AND Key ACTION (KA) in the NATIONAL Policy OF Climate Change [7]

Principle (P), Strategic Thrust (ST) and Key Action (KA)

P1: Development on a sustainable path

Integrate climate change responses into national development plans to fulfil the country's aspiration for sustainable development.

$\rightarrow$ ST1: Facilitate the harmonisation of existing policies to address climate change adaptation and mitigation in a balanced manner.

$\rightarrow$ ST2: Institute measures to make development climate-resilient through low carbon economy to enhance global competitiveness and attain environmentally sustainable socio-economic growth.

$\rightarrow$ ST3: Support climate-resilient development and investment including industrial development in pursuit of sustainable socio-economic growth.

- $11 \mathrm{KA}$

P2: Conservation of environment and natural resources

Strengthen implementation of climate change actions that contribute to environmental conservation and sustainable use of natural resources.

$\rightarrow$ ST4: Adopt balanced adaptation and mitigation measures to strengthen environmental conservation and promote sustainability of natural resources.

$\rightarrow$ ST5: Consolidate the energy policy incorporating management practices that enhances renewable energy (RE) and energy efficiency (EE).

- $12 \mathrm{KA}$

P3: Coordinated implementation

Incorporate climate change considerations into implementation of development programmes at all levels.

$\rightarrow$ ST6: Institutionalise measures to integrate cross-cutting issues in policies, plans, programmes and projects in order to increase resilience to climate change.

$\rightarrow$ ST7: Support knowledge-based decision making through intensive climate related research and development and capacity building of human resources.

- $10 \mathrm{KA}$

P4: Effective participation

Improve participation of stakeholders and major groups for effective implementation of climate change responses.

$\rightarrow$ ST 8: Improve collaboration through efficient communication and coordination among all stakeholder for effective implementation of climate change responses.

$\rightarrow$ ST9: Increase awareness and community participation to promote behavioural responses to climate change.

\section{- $6 \mathrm{KA}$}

P5: Common but differentiated responsibilities and respective capabilities International involvement on climate change will be based on the principle of common but differentiated responsibilities and respective capabilities.

$\rightarrow$ ST10: Strengthen involvement in international programmes on climate change based on the principle of common but differentiated responsibilities and respective capabilities.

- $4 \mathrm{KA}$

1) Mainstreaming climate change through wise management of resources and enhanced environmental conservation resulting in strengthened economic competitiveness and improved quality of life;
2) Integration of responses into national policies, plans and programmes to strengthen the resilience of development from arising and potential impacts of climate change; and

3) Strengthening of institutional and implementation capacity to better harness opportunities to reduce negative impacts of climate change.

The National Policy on Climate Change comprises of 5 major principles, 10 strategic thrusts and 43 key actions [7] which have been summarised into Table I:

\section{RESUlt AND DiscUSSION}

\section{A. The Relationship between the National Policy on Climate Change and the Aquaculture Sector}

TABLE II: OPINIONS FROM RESPONDENTS CORRESPONDING TO THE PRINCIPLE, STRATEGIC THRUST AND KEY ACTION IN THE NATIONAL POLICY ON ClimATE CHANGE

\begin{tabular}{ll}
\hline \hline Opinions from Respondents & $\begin{array}{l}\text { Principle (P) - Strategic Thrust } \\
\text { (ST) - Key Action (KA) }\end{array}$ \\
\hline - It can help guiding development & P1-ST1-KA1 \\
and practices & P1-ST2-KA5 \\
- Any strategies related to natural & P2-ST4-KA13 \\
waterbodies & P3-ST6-KA25 \\
- Research findings and proofs are & P3-ST6-KA27 \\
needed to be delivered to the & P3-ST7-KA28 \\
aquaculture industry & P3-ST7-KA32 \\
- Availability of resources & P3-ST7-KA33 \\
- By educating on how to reduce \\
the contributor factor that increase \\
the climate change, then follow up \\
\begin{tabular}{l} 
with regulation and enforcement \\
\hline \hline
\end{tabular}
\end{tabular}

Responses from respondents have been summarised and tabulated with the corresponding principles, strategic thrusts and key action in the National Policy on Climate Change in Table II. A respondent commented that the incorporation of climate change strategy(s) can help guide development and practices of the aquaculture sector. This statement is in line with the action of mainstreaming climate change which is referred to as the implementation process of actions to address the climate change considerations (the causes and consequences of climate change) as part of a broader suite of measures within existing development processes and decision cycles [8].

Strategies for climate change responses and strategies for sustainable development are highly interactive [9]. Therefore, integration of climate change responses and implementation of climate-friendly measures and technologies in the aquaculture sector would ensure the sector to be sustainable and climate-resilient (P1 - ST2 - KA5).

The development of aquaculture sector on sustainable path necessitates systematic reviews and the integration of climate change responses (both adaptation and mitigation in a balanced manner) into the development plans, followed by harmonising them with the existing policies to address the natural resources and environment closely related to the aquaculture sector, for instance, water, coastal and marine (P1 - ST1 - KA1). Adaptation and mitigation have the potential to contribute to sustainable development and are needed to work together to reduce risks of disruptions from climate change [9]. 
However, limited governance, technical, financial, and institutional capacities are often the major limitations in effective implementation of climate change strategies. In Pakistan, for instance, the major challenge in the Framework for Implementation of National Climate Change Policy Pakistan (NCCP) is related to the significant cost implication, both financial and human [10]. Other than financial support, technological solutions and assistance play a key role in effectively addressing the impacts of climate change as well [11]. For designing and implementing climate policies effectively, it is important to ensure that the key factors (institutional arrangements, governance mechanisms, and financial resources) are aligned with the goals [12]. A respondent suggested that 'availability of resources' contributes to effective incorporation of the climate change strategy(s) into the aquaculture sector. The implementation of climate change actions have to be strengthened by adopting balanced adaptation and mitigation measures as well as mobilising financing and technical assistance into the aquaculture sector (P2 - ST4 - KA13).

The opinions from all of the respondents are highly in line with Principle 3 in the National Policy on Climate Change that suggests the incorporation of climate change considerations into implementation of development programmes at all levels, in this context, the aquaculture sector. Climate change are expected to undermine planned development outcomes in many countries and affected every sector of society, including water resources, food production, energy use, transportation and commerce, recreation, and even national security [13], [14]. Thus, integration of climate change resilience should be a major agenda in the development of aquaculture sector.

Climate change considerations and institutionalised measures should be incorporated into implementation of development programmes at all levels (policies, plans, programmes and projects) to increase resilience to climate change (P3 - ST6). For instance, adaptation should also be incorporated at several stages of the national policy cycle [15]. One of the respondents has made a remark that 'any strategies related to natural waterbodies' needs to be incorporated into the aquaculture sector. A comprehensive legal and institutional framework has become a fundamental requirement that clearly stipulates the main principles and strategies that need to be adhered to for sustainable use and conservation of natural resources such as water [16]. Climate change measures should be integrated into policies, plans, programmes and projects in natural resources and environment especially water, coastal and marine (KA25). In conjunction with this, an enhanced coordinating mechanism is required to oversee the planning, implementation and monitoring of climate change measures (KA27).

Climate related research and development and capacity building of human resources are essential in supporting knowledge-based decision making in developing the aquaculture sector (ST7). Authorities or stakeholders should establish and implement research and development (R\&D) agenda on climate change taking into account the agriculture and food security, in this context, the aquaculture sector (KA28).

One of the respondents stated that 'research findings and proofs are needed to be delivered to the (aquaculture) industry' as the indigenous and scientific knowledge from collaborative participation are essential in making the institutional capacity of implementation effective. A coordinating mechanism is needed to oversee R\&D activities, information dissemination, avoidance of duplication, and to support decision making (KA32).

It is also essential to implement institutionalised measures to strengthen effective linking of climate science and policy (KA33). For instance, a regional or sub-regional effort is needed to better integrate scientific knowledge and to put into place coherent fisheries policies [17]. A respondent suggested that climate change strategy(s) can be effectively incorporated 'by educating on how to reduce the contributor factor that increase the climate change, (and) then follow up with regulation and enforcement'. Availability of better and more relevant scientific information on climate change impacts are important for decision-makers to strengthen the aquaculture sector. In order to achieve better communication and raise awareness, the policy-makers and the aquaculture stakeholders should work hand in hand to improve their understanding and action on different climate change aspects.

Capacity to use scientific information should be improved for policy purposes, as well as providing scientific, legal and institutional support to the aquaculture sector stakeholders to build a climate-resilient aquaculture sector. Therefore, it is necessary to establish regional climate science centres that have the institutional capacities to support and inform climate change adaptation activities [17].

\section{B. Climate Resilient Aquaculture Sector}

The process of achieving sustainable aquaculture is complicated by the variable and uncertain climate change impacts aquaculture face. Farmers, scientists and policy makers should work hand-in-hand to produce, synthesise and package scientific knowledge so that to improve understanding on vulnerabilities, and hence reduce and/or cope with them [18].

Aquaculture is moving towards intensive, controlled environment production units with control and monitoring on the life support parameters such as water, dissolved oxygen, temperature, $\mathrm{pH}$, alkalinity, ammonia-nitrogen, nitrite, nitrate, and carbon dioxide [19]. Control and monitoring systems in the aquaculture sector are aided by the utilisation of control devices. The control devices, for instance sensors, motors, pumps, electronics, computer and software, must be precisely controlled to optimise the production of aquaculture system [20] by providing stable and optimal conditions for the fish with less stress and better growth [21].

Implementation of a control and monitoring system in the aquaculture sector is suggested by some of the respondents to make the aquaculture to be climate resilient. Adverse environment impact can be reduced in a continuously controlled and monitored environment, with gearing of technology driven solution to cultivation and production process, to improve the productivity and achieve optimal growth [20].

A respondent suggested that 'indoor aquaculture which is an all enclose system with temperature control' could be climate resilient. Recirculation aquaculture systems (RAS) 
can be a wise choice as it is a new fish farming method that keeps fish at high densities, in indoor tanks with a "controlled" environment in the aspects of clean water circulation at a temperature and dissolved oxygen content that is optimum for growth [22]. Water temperature has to be maintained year-round at preferences depending on the fish species as it is an important factor that influence feeding and growth rates of cultured fish [22].

Water temperature has been identified as one of the important parameters affecting the growth of fish in aquaculture sector and has to be monitored closely. There is a suggestion from a respondent stating that aquaculture sector can be climate resilient 'by having a control system that is very sensitive to even slight changes of climate like coral reef as monitoring tools since it is very sensitive'. Temperature has to be monitored continuously and precisely in order to optimise production, reduce stress and minimise risk of disease [19].

Two respondents unanimously stated that 'sustainable fishery management' and 'improvement of hatchery practices' are the criteria for an aquaculture sector to be climate resilient. Sustainable fisheries management is achievable by taking into account the ecological, social and economic components (see Fig. 1) [23], [24]. Therefore, efficiency and sustainability of aquaculture operations can be improved by implementation of best management practices [25] which provide constant monitoring and control, strengthening environmental protection and sustainable aquaculture development in the coastal areas [26].

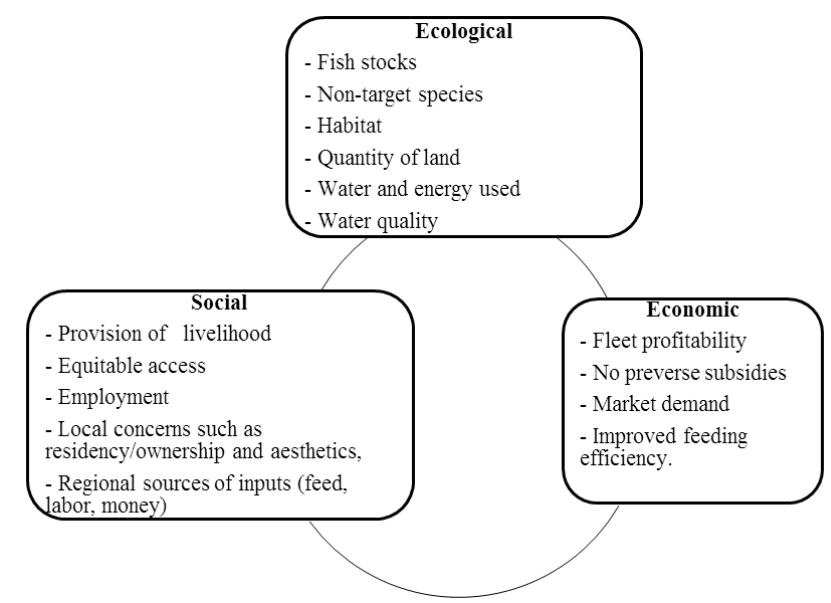

Fig. 1. Key components of overall sustainability. [23], [24].

Regulations on the growing environment have been made for some of the species at earlier stages, for instance indoor hatcheries, yet the mature species are usually exposed to a more natural environment [27]. It is recommended to use recirculation system with a controlled environment, for instance the effective and the most competitive land based farms with cage farming, to keep the fast-growing small fish before releasing them into the large sea cages for grow-out [21]. Recirculation with less disease outbreaks and better control on the hatchery parameters enhances the aquaculture production [21].

Another respondent suggested that the aquaculture sector would be climate resilient depending on the capacity in the sector, plans and technologies that help farmers cope with climate change. The capacity of controlling and planning on the harvesting time, and then conveyance of products, additionally gives a few climate resilience measures to aquaculture sectors [27]. Improvement on management and capacity of institutions is essential in helping people adapt and provide policy advice and hence mainstreaming climate change adaptation [18].

\section{CONCLUSION}

Better understanding of the potential climate change policy impact mechanisms on aquaculture sector enables the policy-makers and stakeholders to plan and implement possible countering measures to achieve sustainability in aquaculture industry. The National Policy on Climate Change is expected to promote aquaculture sector in Malaysia as it is aimed to tackled the climate change impacts and hence help developing aquaculture sector in a sustainable and climate-resilient manner.

\section{ACKNOWLEDGMENT}

Much appreciations go to the respondents for their kind cooperation in completing the survey questionnaire with precious opinions and suggestions which help making this research a success. The authors also thank the Malaysian Ministry of Higher Education for providing the research grant (NRGS0005) for this research.

\section{REFERENCES}

[1] S. Chen, B. Mulgrew, and P. M. Grant, "A clustering technique for [1] food and agriculture organization of the United Nations," Fishery Statistical Collections, 2016.

[2] B. A. Costa-Pierce, Ecological Aquaculture: The Evolution of the Blue Revolution, 1st ed. U.K.: Blackwell Science Ltd, 2002, ch 1, pp. 3-13.

[3] R. Hamdan, F. Kari, and N. M. Satar. (2010). Socio-economic vulnerability to climate change: impact assessment on aquaculture farmers in Sarawak, Malaysia. [Online]. Available: umconference.um.edu. my/upload/163-1/Paper

[4] Food and Agriculture Organization of the United Nations. (2016) National Aquaculture Sector Overview: Malaysia. [Online]. Available: http://www.fao.org/fishery/countrysector/naso_malaysia/en

[5] Department of Fisheries Malaysia. (2016) Fisheries Annual Statistics [Online]. Available: http://www.dof.gov.my/index.php/pages/view/82

[6] K. Y. Soheila and S. Bahram, "The effects of climate change on aquaculture," International Journal of Environmental Science and Development, vol. 1, no. 5, December 2010.

[7] Ministry of Natural Resources and Environment Malaysia, Dasar Perubahan Iklim Negara (National Policy on Climate Change), Ministry of Natural Resources and Environment Malaysia, Malaysia, 2010.

[8] United Nations Development Group, "Integrating climate change considerations in the country analysis and the UNDAF," A Guidance Note for United Nations Country Teams, April 2010.

[9] F. Denton, T. J. Wilbanks, A. C. Abeysinghe, I. Burton, Q. Gao, M. C. Lemos et al., "Climate-resilient pathways: adaptation, mitigation, and sustainable development," Climate Change 2014: Impacts, Adaptation, and Vulnerability. Part A: Global and Sectoral Aspects. Contribution of Working Group II to the Fifth Assessment Report of the Intergovernmental Panel on Climate Change, Cambridge University Press, Cambridge, U. K. and New York, U. S.A., 2014, pp. 1101-1131.

[10] Climate Change Division, "Framework for implementation of climate change policy (2014 - 2030)," Government of Pakistan, Islamabad, Pakistan, November 2013.

[11] Asian Development Bank, "Technologies to support climate change adaptation," Mandaluyong City, Philippines, 2014.

[12] Intergovernmental Panel on Climate Change, "Climate change 2014 mitigation of climate change," The Fifth Assessment Report of the 
Intergovernmental Panel on Climate Change, Cambridge University Press, Cambridge, U. K. and New York, U. S. A., 2014.

[13] I. F. Camara, "Mainstreaming climate change resilience into development planning in the Gambia," Climate Change: IIED Country Report, IIED, London, April, 2013.

[14] United States Environmental Protection Agency. (2010). Climate change and society. Fact Sheet. [Online]. Available: www.epa.gov/climatechange

[15] Organisation for Economic C0-Operation and Development, Policy Statement on Integrating Climate Change Adaptation into Development Co-operation, October 2009.

[16] K. C. Urama and N. Ozor, "Impacts of climate change on water resources in Africa: the role of adaptation," Climate Adaptation, African Technology Policy Studies Network (ATPS), December 2010.

[17] M. C. Badjeck, R. E. Katikiro, M. Flitner, N. Diop, and K. Schwerdtner Máñez, "Envisioning 2050: Climate change, aquaculture and fisheries in West Africa," Workshop Report No. 2011-09, Dakar, Senegal, April 2010.

[18] The World Fish Center, "Fisheries and aquaculture can provide solutions to cope with climate change," Issues Brief: 1701, Penang, Malaysia, 2007.

[19] J. M. Ebeling, Computer Monitoring \& Control Technology, Controlled Environment Agriculture Center, The University of Arizona, 2015.

[20] N. P. Mahalik and K. Kim, "Aquaculture monitoring and control systems for seaweed and fish farming," World Journal of Agricultural Research, Science and Education Publishing. vol. 2, no. 4, pp. 176-182, August 2014.

[21] J. Bregnballe, "An introduction to the new environmentally friendly and highly productive closed fish farming systems," A Guide to Recirculation Aquaculture, The Food and Agriculture Organization of the United Nations (FAO) and EUROFISH International Organisation, 2015.

[22] L. A. Helfrich and G. Libey, Fish Farming in Recirculating Aquaculture Systems (RAS), Department of Fisheries and Wildlife Sciences, Virginia Tech, 2004.

[23] Marine Resources Assessment Group, Towards Sustainable Fisheries Management: International Examples of Innovation, MRAG Ltd, London, 2010.

[24] W. A. Wurts, "Sustainable aquaculture in the twenty-first century," Reviews in Fisheries Science, CRC Press LLC. vol. 8, no. 2, pp. 141-150, 2000

[25] The United States Agency for International Development, Sustainable Fisheries and Responsible Aquaculture: A Guide for USAID Staff and Partners, University of Rhode Island, June 2013.
[26] A. Frankic and C. Hershner, "Sustainable aquaculture: developing the promise of aquaculture," Aquaculture International, Kluwer Academic Publishers, vol. 11, pp. 517-530, June 2003.

[27] B. Mapstone, P. Appleford, K. Broderick, R. Connolly, J. Higgins, A Hobday et al., National Climate Change Adaptation Research Plan for Marine Biodiversity and Resources, National Climate Change Adaptation Research Facility, Gold Coast, pp. 68, 2010.

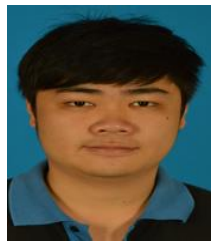

Chee Sheng Woon was born in 1991. He received his bachelor of science in environmental science from Universiti Sabah Malaysia, in 2014. He is currently a postgraduate student of the Environmental Science Programme in Universiti Malaysia Sabah. His current research interests about climate change policy and aquaculture sector.

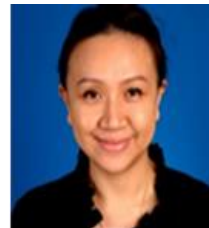

Carolyn Payus received her $\mathrm{PhD}$ degree in environmental science from Universiti Kebangsaan Malaysia, in 2015. She is currently the head of programme for environmental science programme in Universiti Malaysia Sabah. She specializes in environment management and bioremediation. Her current research interests about atmospheric chemistry, environmental bioinformatics and steroid-hormones contamination.

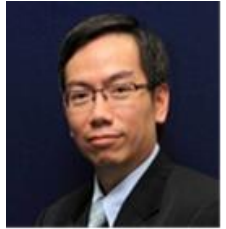

Leong Wan Vun received his $\mathrm{PhD}$ degree in environmental conservation from Universiti Kebangsaan Malaysia, in 2002. He is currently a lecturer with environmental science programme in Universiti Malaysia Sabah. $\mathrm{He}$ specializes in environmental management.

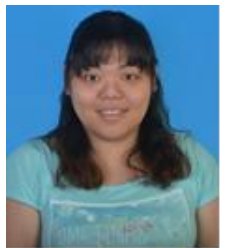

Wei Peng Lee was born in 1991. She is a MSc candidate in environmental science at the Faculty of Science and Natural Resources of Universiti Malaysia Sabah, Malaysia. Her current research focus is into environmental pollutants in aquaculture ponds. 